\title{
Giant ionospheric disturbances observed with the SuperDARN Hokkaido HF radar and GPS network after the 2011 Tohoku earthquake
}

\author{
Tadahiko Ogawa $^{1}$, Nozomu Nishitani ${ }^{2}$, Takuya Tsugawa ${ }^{1}$, and Kazuo Shiokawa ${ }^{2}$ \\ ${ }^{1}$ National Institute of Information and Communications Technology, Tokyo 184-8795, Japan \\ ${ }^{2}$ Solar-Terrestrial Environment Laboratory, Nagoya University, Nagoya 464-8601, Japan
}

(Received December 22, 2011; Revised August 1, 2012; Accepted August 2, 2012; Online published January 28, 2013)

\begin{abstract}
Giant ionospheric disturbances induced by the 2011 off the Pacific coast of Tohoku Earthquake $\left(M_{\mathrm{w}} 9.0\right)$ on 11 March 2011 are studied by using data from the SuperDARN Hokkaido HF radar and GPS receiver network (GEONET) in Japan. The HF radar observations revealed strong disturbances to the north of Hokkaido that propagated northward at velocities of $6.7-1.8 \mathrm{~km} / \mathrm{s}$ triggered by northward-propagating seismic surface waves. An induction magnetometer in Hokkaido recorded part of the seismic wave propagation from the epicenter. After the passage of the $6.7-1.8 \mathrm{~km} / \mathrm{s}$ waves the radar observed northward-propagating disturbances (343-136 $\mathrm{m} / \mathrm{s}$ ) due to atmospheric gravity waves (AGW) perhaps excited near the epicenter. Interestingly, the radar first detected peculiar disturbances with periods of about 2-4 min caused by the acoustic resonance. GEONET, which covers the area on the south of the radar field of view, provided total electron content (TEC) data. Comparisons between radar and TEC observations indicate the following: (1) $6.7-1.8 \mathrm{~km} / \mathrm{s}$ waves observed with the radar do not always have counterparts in TEC. (2) Acoustic waves of $1.3-0.7 \mathrm{~km} / \mathrm{s}$ identified in TEC are not observed with the radar. (3) Disturbances caused by both AGW and acoustic resonance are simultaneously discernible in both TEC and radar data.
\end{abstract}

Key words: Earthquake, ionospheric disturbance, Hokkaido radar, GPS, TEC, Rayleigh wave, acoustic-gravity wave, acoustic resonance.

\section{Introduction}

The ionosphere is strongly disturbed by energetic sources such as earthquakes, volcanic eruptions, etc. (e.g., Blanc, 1985). Various kinds of waves excited by earthquake and earthquake-related tsunamis propagate upward/obliquely in the atmosphere to induce ionospheric disturbances near the source and at large distances from it (e.g., Liu et al., 2006, 2010, 2011; Astafyeva et al., 2009; Tsugawa et al., 2011; Rolland et al., 2011a). Acoustic-gravity waves with velocities of the order of a few hundred meters/s are well-known (e.g., Artru et al., 2004, 2005; Liu et al., 2006; Rolland et al., 2010). Acoustic waves of about $0.5-1.5 \mathrm{~km} / \mathrm{s}$ are also generated (e.g., Calais and Minster, 1995; Afraimovich et al., 2001; Heki and Ping, 2005; Otsuka et al., 2006; Liu et al., 2010; Chen et al., 2011). Acoustic waves induced by high-speed (2-4 km/s) Rayleigh waves propagating on the Earth's surface also disturb the ionosphere (e.g., Yuen et al., 1969; Tanaka et al., 1984; Ducic et al., 2003; Liu et al., 2006; Nishitani et al., 2011; Rolland et al., 2011b). Peculiar ionospheric oscillation with a period of about $4 \mathrm{~min}$, caused by the acoustic resonance between the ground surface and the lower thermosphere $(\sim 100 \mathrm{~km}$ altitude), have been observed near epicenter for long hours (Saito et al., 2011; Tsugawa et al., 2011). The above-

Copyright (C) The Society of Geomagnetism and Earth, Planetary and Space Sciences (SGEPSS); The Seismological Society of Japan; The Volcanological Society of Japan; The Geodetic Society of Japan; The Japanese Society for Planetary Sciences; TERRAPUB.

doi:10.5047/eps.2012.08.001 mentioned "coseismic" ionospheric disturbances have been observed mainly by means of HF-Doppler sounding (e.g., Yuen et al., 1969; Najita and Yuen, 1979; Tanaka et al., 1984; Artru et al., 2004; Liu et al., 2006) and GPS signal reception (e.g., Ducic et al., 2003; Otsuka et al., 2006; Tsugawa et al., 2011). In addition to these, an incoherent scatter radar (Kelley et al., 1985), an over-the-horizon radar (Occhipinti et al., 2010) and routine ionosondes (e.g., Leonard and Barnes, 1965; Liu and Sun, 2011; Maruyama et al., 2011) were utilized to detect coseismic signature in the ionosphere.

The 2011 off the Pacific coast of Tohoku Earthquake (hereafter called the 2011 Tohoku earthquake) occurred at 1446:23 JST (Japan Standard Time $=\mathrm{UT}+9 \mathrm{~h}$ ) on 11 March 2011 with $M_{\mathrm{w}} 9.0$ and at an epicenter of $\left(38.32^{\circ} \mathrm{N}\right.$, $142.37^{\circ}$ E) (U.S. Geological Survey, 2011). This giant earthquake gave a rare opportunity for studying detailed characteristics of ionospheric disturbances over and around Japan. Fruitful results have been obtained by analyzing data from an extremely dense GEONET (GPS Earth Observation Network), ionosondes and an HF radar in Japan, as mentioned above.

An HF radar located in Hokkaido belongs to a worldwide HF radar network, called the SuperDARN (Super Dual Auroral Radar Network) (Greenwald et al., 1995; Chisham et al., 2007), and is capable of probing the ionosphere over the Sea of Okhotsk to the north of Hokkaido. On this day this radar, equipped with 16 narrow beams, was operated with a time resolution of $1 \mathrm{~min}$ for each beam until 1500:12 


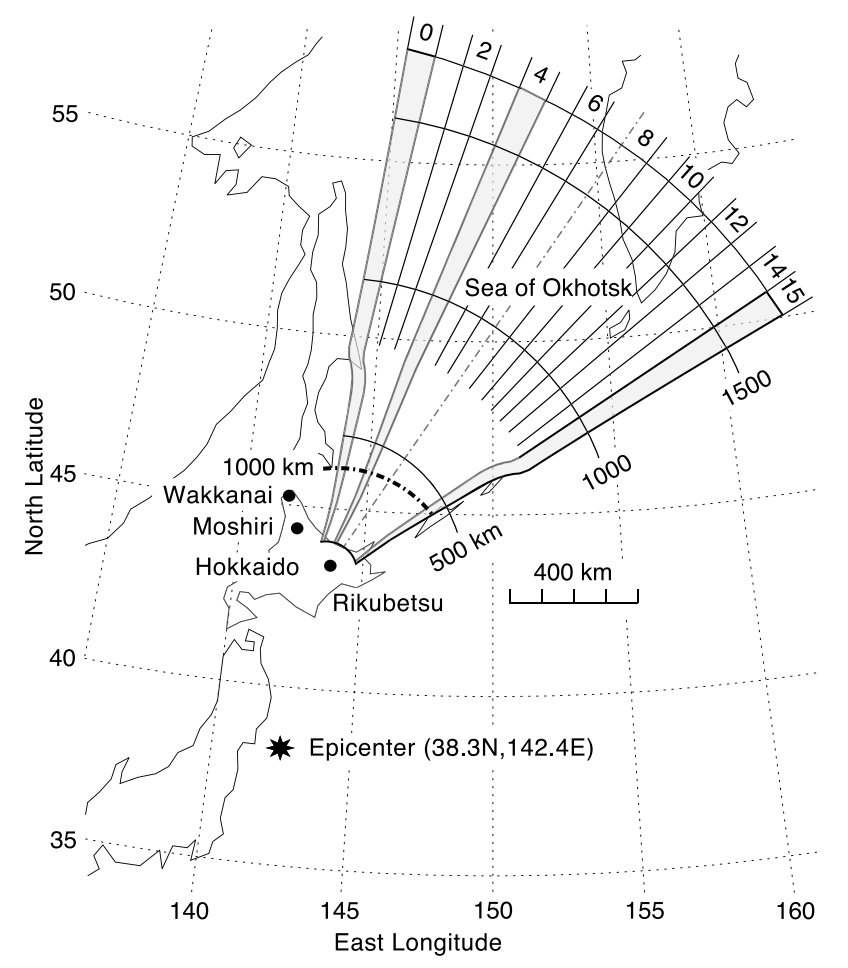

Fig. 1. Field of view of the SuperDARN Hokkaido radar with sixteen beams at Rikubetsu. Approximate ground ranges from Rikubetsu are shown. A thick dotted broken curve represents points of $1000 \mathrm{~km}$ from the epicenter. Induction magnetometer and ionosonde are located at Moshiri and Wakkanai, respectively. Great circle distances from the epicenter to Wakkanai, Moshiri and Rikubetsu are 762, 672 and 588 km, respectively.

JST after the mainshock at 1446:23 JST. Fortunately, after 1500:12 JST the radar began to observe echoes on one specific beam with a time resolution of $8 \mathrm{~s}$, enabling us to know detailed behavior of the echo power and Doppler velocity with a spatial resolution of about $22.5 \mathrm{~km}$. Nishitani et al. (2011) have presented initial results to discuss northwardpropagating disturbances from the epicenter at $6.2-3.5 \mathrm{~km} / \mathrm{s}$ with a velocity dispersion with time. This paper analyzes in detail HF radar echo data together with GPS total electron content (GPS-TEC) data from GEONET to discuss propagation characteristics of high-speed waves (6.7-1.8 $\mathrm{km} / \mathrm{s}$ ), atmospheric gravity waves (AGW; 343-136 m/s) and acoustic waves $(1.3-0.7 \mathrm{~km} / \mathrm{s})$, and acoustic resonance after the mainshock.

\section{Instrumentation}

We use two observation instruments, that is, the SuperDARN Hokkaido HF radar and GEONET. GEONET of about 1240 GPS receivers with an average distance between two receivers of about $20 \mathrm{~km}$ provides data of GPS-TEC between the GPS altitude $(20,200 \mathrm{~km})$ and the ground every $1 \mathrm{~s}$ (e.g., Saito et al., 2011) or $30 \mathrm{~s}$ (e.g., Tsugawa et al., 2011). This paper uses 30-s sampling data.

Figure 1 shows a field of view (FOV) of the HF radar located at Rikubetsu $\left(43.53^{\circ} \mathrm{N}, 143.61^{\circ} \mathrm{E} ; 588 \mathrm{~km}\right.$ from the epicenter) in Hokkaido. To detect echoes from the ionosphere over the Sea of Okhotsk, the FOV is covered with 16 narrow oblique beams (beams $0,1,2, \ldots, 15$; each two-way horizontal beam width of about $3.5^{\circ}$ at $11 \mathrm{MHz}$ ) over an azimuth sector of $52^{\circ}$. The beams have maximum sensitivity at elevation angles of $15^{\circ}-35^{\circ}$ (depending on radar frequency). During the period of our interest, the frequency was around $11 \mathrm{MHz}$, and the first range gate was set to $180 \mathrm{~km}$ with a range resolution of $45 \mathrm{~km}$. The radar was operated with two beam scan modes; that is, the "normalscan" mode before 1500:12 JST and the "themisscan" mode (named after the spacecraft program name) after 1500:12 JST. In the normalscan mode, the beam was sequentially scanned from beam 15 to beam 0 with a step of $3.24^{\circ}$ in azimuth, a 3 -s integration time for each beam and a scan repeat time of $1 \mathrm{~min}$. In the themisscan mode, 2 min was spent to complete one scan of the radar FOV excluding beam 0 ; that is, beam 4 and other beams were alternatively scanned in order of beams $15,4,14,4, \ldots, 2,4,1$ and 4 with a 4-s integration time for each beam, resulting in a sampling of beam 4 every $8 \mathrm{~s}$ and other beams every $2 \mathrm{~min}$. Note that as shown in Fig. 1, beam 4 directed toward NNE is closely aligned along the radial direction away from the epicenter. This fact enables us to know approximate velocity of ionospheric disturbances that propagate toward NNE along the radial direction from the epicenter. This paper mainly analyzes radar echo data on beam 4 with a time resolution of 1 min or $8 \mathrm{~s}$. Additionally, the radar FOV is on the north of the GEONET coverage.

GPS-TEC is given by an integration of electron density along the satellite-receiver line of sight, and is mainly determined by the electron density distribution at the 250-350 $\mathrm{km}$ altitudes. On the other hand, the HF radar probes, in principle, motion and fluctuation of the ionospheric plasma at around a fixed altitude (assumed $250 \mathrm{~km}$ in our case). Therefore, as shown below, disturbances detected by the radar may not always have counterparts in GPS-TEC observations and vice versa. 

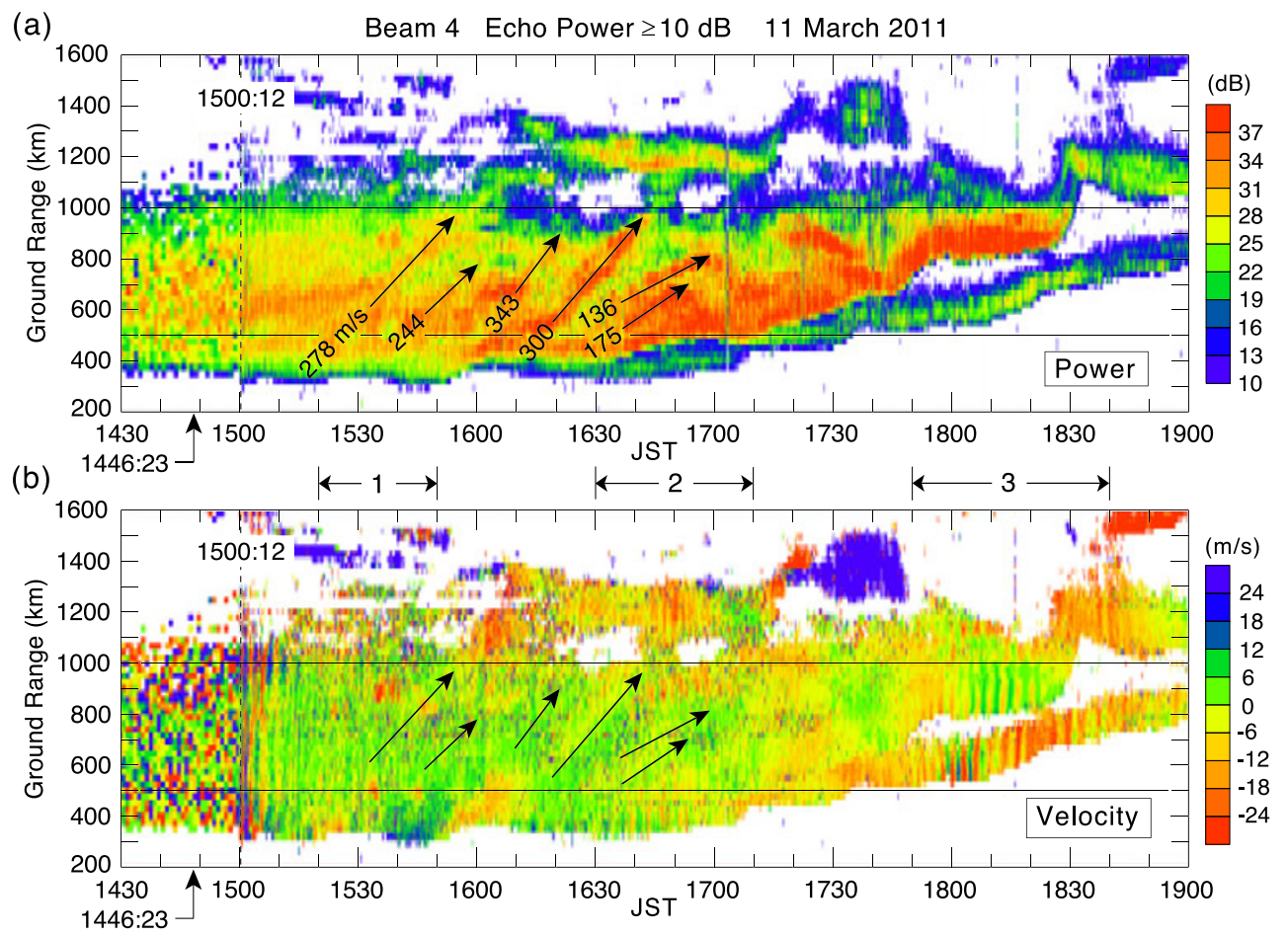

Fig. 2. Time and ground range variations of (a) echo power and (b) Doppler velocity on beam 4. Data with echo power higher than $10 \mathrm{~dB}$ are displayed. Propagation velocity of each gravity wave shown in (a) is overlaid in (b). The themisscan starts at 1500:12 JST after the mainshock at 1446:23 JST.

\section{Observation and Analysis 3.1 Echo feature}

Most of nighttime echoes over the Sea of Okhotsk previously observed with our HF radar returned from decameterscale field-aligned plasma irregularities in the ionosphere (e.g., Nishitani and Ogawa, 2005; Shiokawa et al., 2008; Ogawa et al., 2009; Suzuki et al., 2009). To the contrary, daytime echoes observed before and after the mainshock on 11 March 2011 were almost due to ground/sea surface (GS) scatter (hereafter called GS-scatter), and not backscatter from ionospheric irregularities. An HF wave radiated obliquely upward from the radar is reflected downward in the $F$ region, then backscattered by irregular GS-scatter structures, and goes back to the radar along the same radio path to be observed as "1-hop" GS-scatter echoes. Under proper conditions, "2-hop" GS-scatter echoes are detected at ranges farther than 1-hop echo ranges (see Fig. 5 as an example, and Nishitani et al. (2011) in detail).

Figure 2 shows time and ground range variations of the echo power (higher than $10 \mathrm{~dB}$ ) and Doppler velocity on beam 4 . Note that the velocity sign is positive (negative) for motion toward (away from) the radar. The mainshock occurred at 1446:23 JST, and the themisscan started at 1500:12 JST. In the figure the "ground range" representing the range on the ground from the radar site is converted from the observed slant range, and is calculated by mapping an ionospheric reflection point (assumed to be $250 \mathrm{~km}$ ) onto the ground. Note that for GS-scatter echoes, a slant range resolution of $45 \mathrm{~km}$ corresponds approximately to a spatial resolution of $22.5 \mathrm{~km}$ when echo data are mapped onto the reflection points. In Fig. 2 the echoes at ranges below about $1250 \mathrm{~km}$ are mostly due to the GS-scatter, and those beyond $1250 \mathrm{~km}$ are partly caused by the backscatter from $F$ region irregularities having velocities far higher than $|30| \mathrm{m} / \mathrm{s}$.

During 1530-1700 JST in Fig. 2(a), there appears northward propagation (136-343 m/s) of the enhanced echo regions caused by northward-propagating AGW that were excited by the earthquake: it is well known that HF radar echo power fluctuates due to focusing and defocusing of HF ray paths caused by electron density perturbations in association with AGW in the $F$ region (e.g., Samson et al., 1990; Ogawa et al., 2009, and references therein). After sunset near 1730 JST, the whole echo regions move northward with time due to the gradual decrease in the $F$ region electron density. The Doppler shift of the GS-scatter echo shown in Fig. 2(b) is caused only by upward (negative Doppler shift) or downward (positive Doppler shift) motion of the ionospheric reflection point. By considering the path geometry of the radar wave, the actual vertical motion is given by $v / 2 \sin \theta$, where $v$ and $\theta$ are the observed line-of-sight velocity and the elevation angle of the ray path, respectively (e.g., Nishitani et al., 2011). The propagation velocity of each AGW shown in Fig. 2(a) is overlaid in Fig. 2(b), where signatures of the AGW propagation are unclear, suggesting that the current AGW did not always induce appreciable upward and downward motions of the $F$ region plasma. It is noted that after the mainshock $\left(M_{\mathrm{w}} 9.0\right)$ at 1446:23 JST, five aftershocks $\left(M_{\mathrm{w}} 6.5-7.9\right)$ and one aftershock $\left(M_{\mathrm{w}} 6.5\right)$ occurred during 1508-1526 JST and at around 1719 JST, respectively (U.S. Geological Survey, 2011). The radar echoes shown in Fig. 2 may be affected more or less by disturbances due to these aftershocks.

\subsection{Initial arrival and northward propagation of dis-} turbances

In this subsection, we analyze the radar echoes during 1457-1510 JST in Fig. 2 to see the characteristics of distur- 

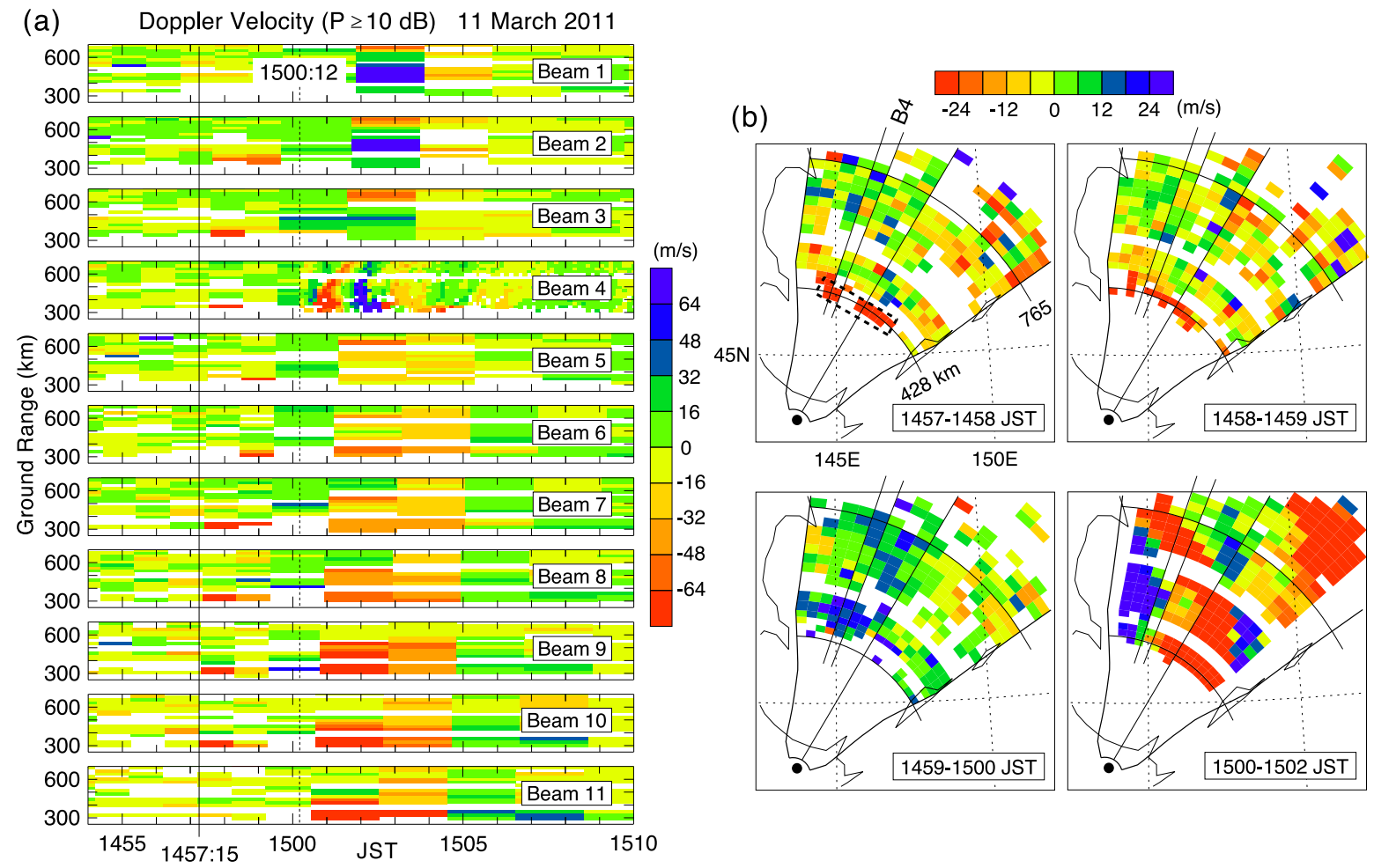

Fig. 3. (a) Time and ground range variations of Doppler velocity (with echo power higher than $10 \mathrm{~dB}$ ) on beams 1-11. (b) Two-dimensional maps of Doppler velocity for four time periods. Beam 4 is marked in each figure.

bances at the early stage. Figure 3(a) gives time and ground range variations of the Doppler velocity on beams 1-11. As can be clearly seen, the initial disturbances with negative Doppler velocities (upward motion of the reflection points) exceeding $60 \mathrm{~m} / \mathrm{s}$ were first detected on beam 10 on which the normalscan began at 1457:15 JST, 10 min 52 s later after the mainshock (1446:23 JST), and then successively on other beams. The themisscan started at 1500:12 JST to observe echoes on beam 13 (not shown), and then successively on beams $4,12,4,11,4, \ldots, 1,4,15,4, \ldots$. The northwardpropagating structures with positive and negative Doppler shifts are not clearly discernible before 1500:12 JST, that is, when the normal scan mode with time resolution of 1 min was in operation, but become clear on beam 4 from 1500:16 JST until about 1508 JST. We believe that these disturbances are associated with the northward-propagation of various seismic surface waves (see below). If the themisscan started at around $1455 \mathrm{JST}$, the radar would detect more detailed echo features during 1457-1500 JST.

Figure 3(b) displays two-dimensional maps of the Doppler velocity for successive four time periods during 1457-1502 JST. As indicated by the dotted rectangle in the 1457-1458 JST panel, the initial disturbances with negative Doppler velocities arrive at the nearest ranges around $1100 \mathrm{~km}$ from the epicenter (see Fig. 1). In the 1458-1459 JST panel these disturbances seem to stay around the 1100 $\mathrm{km}$ range. In the next two panels (1459-1500 and 15001502 JST) the disturbances with high negative and positive Doppler velocities propagate northward (see figure 5 of Nishitani et al. (2011) in detail). It is sure that these disturbances began to be detected by the radar before the start of the themisscan.
Figure 2(b) is enlarged in Fig. 4(a), where the echoes within the dotted gray rectangle at ground ranges of 900$1100 \mathrm{~km}$ are partly contaminated by 2-hop echoes (see Fig. 5 in detail) and are not considered in this paper. Again, very clear, northward-propagating structures are seen after 1500:12 JST in Fig. 4(a). Figure 4(b) displays time variation of the $d H / d t$ component recorded at a sampling rate of $64 \mathrm{~Hz}$ by an induction magnetometer under the ground at Moshiri $\left(44.37^{\circ} \mathrm{N}, 142.27^{\circ} \mathrm{E}\right.$; Fig. 1), $672 \mathrm{~km}$ north of the epicenter (Shiokawa et al., 2010). Here, $d H / d t$ denotes the time derivative of the horizontal component of the geomagnetic field. The rapid oscillations of $d H / d t$ started at around 1448:20 JST are due to the mechanical shaking of the magnetometer caused by the seismic waves.

To see smooth time variation of $d H / d t$, the data averaged over $4 \mathrm{~s}$ are shown in Fig. 4(c), where five times (1448:03, 1448:30, 1449:42, 1450:39 and 1452:36 JST) that are selected somewhat arbitrarily are marked. The weak shaking with small amplitudes started at around 1448:30 JST. By considering the distance $(672 \mathrm{~km})$ from the epicenter to Moshiri, the propagation velocity of this disturbance is estimated to be $5.3 \mathrm{~km} / \mathrm{s}$. The stronger shaking started at around 1449:42 JST, and the strongest one at around 1450:39 JST. The shaking began to subside at around 1452:36 JST. When we assume that these strong shakings in addition to the weak shaking that started at 1448:30 JST are due to northward-propagating seismic waves that were generated by a pulse-like shock at the epicenter, the propagation velocities corresponding to the times of 1449:42, 1450:39 and 1452:36 JST are 3.4, 2.6 and $1.8 \mathrm{~km} / \mathrm{s}$, respectively (If this assumption is not the case, the estimated velocities may be meaningless. We will show below that 
(a)
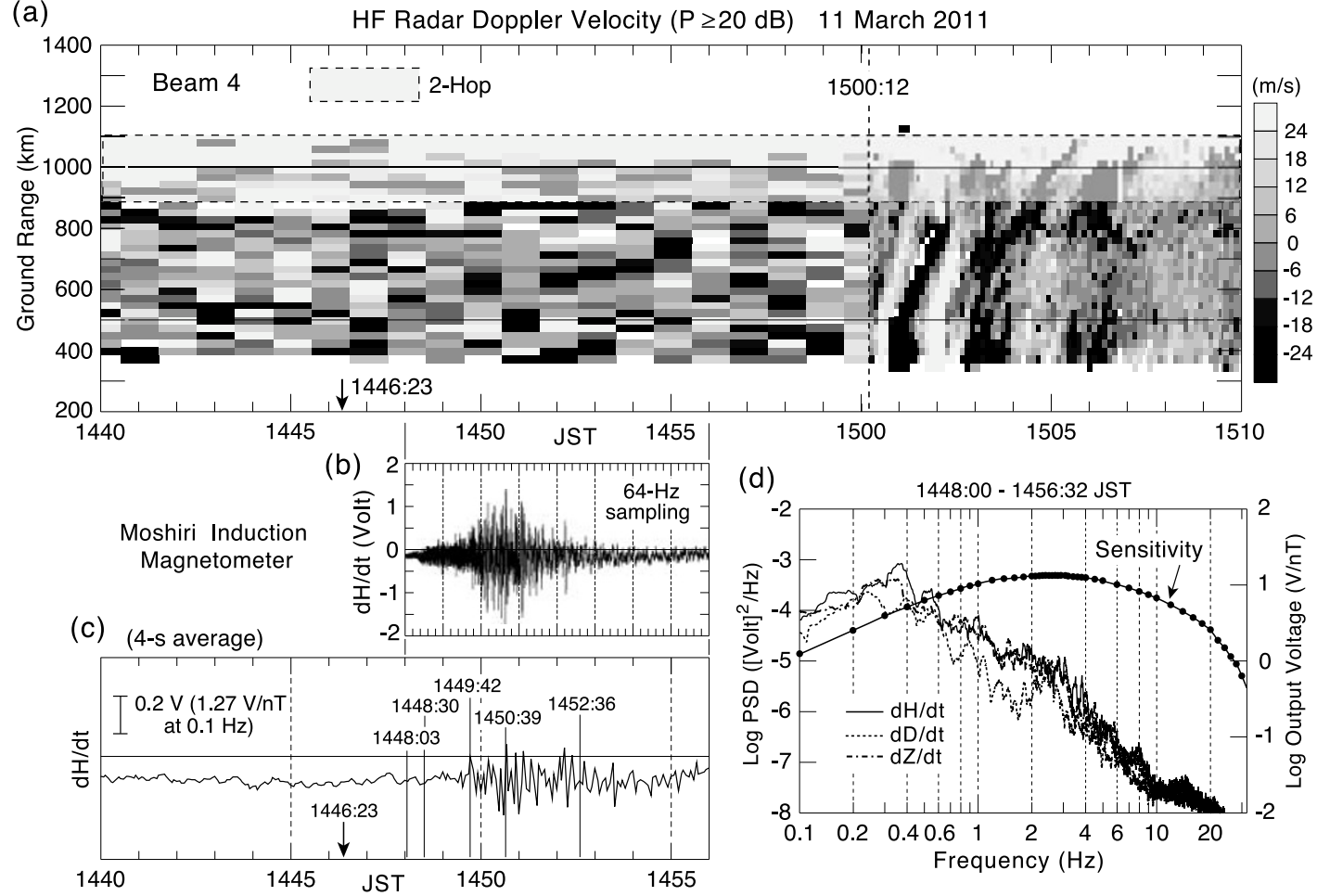

Fig. 4. (a) Time and ground range variations of Doppler velocity (with echo power higher than $20 \mathrm{~dB}$ ) on beam 4 . Echoes within a dotted gray rectangle are partly contaminated by 2-hop echoes. (b) Moshiri induction magnetometer record of $d H / d t$ at a sampling rate of $64 \mathrm{~Hz}$. (c) Moshiri induction magnetometer record of $d H / d t$ averaged over $4 \mathrm{~s}$. (d) Frequency spectra of $d H / d t, d D / d t$ and $d Z / d t$. Sensitivity of the magnetometer is also plotted.

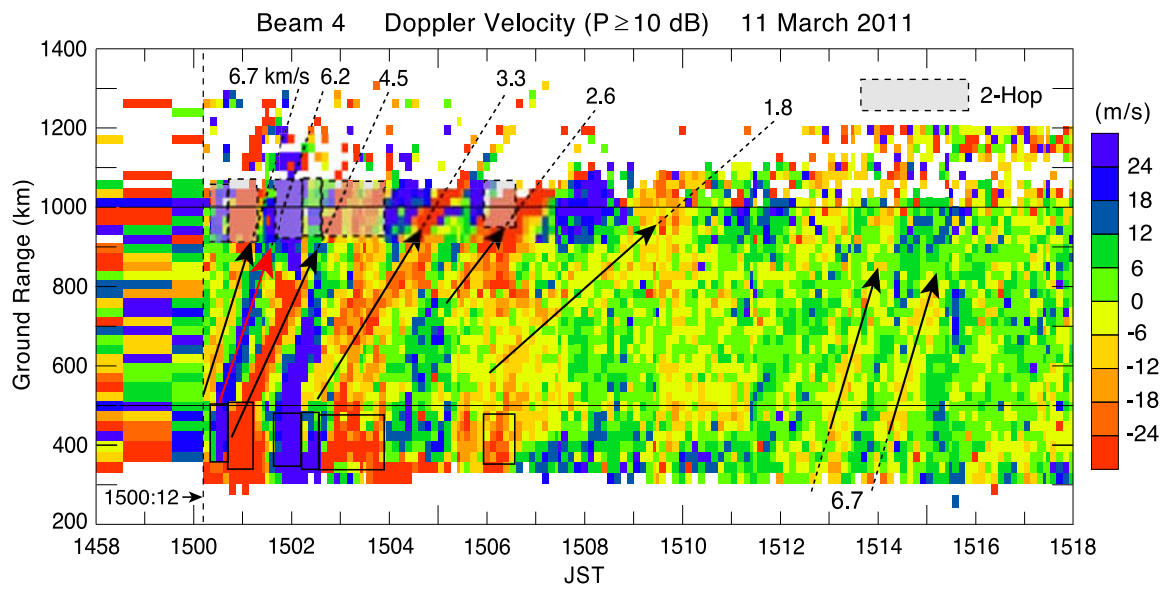

Fig. 5. Time and ground range variations of Doppler velocity (with echo power higher than $10 \mathrm{~dB}$ ) on beam 4 . Propagation velocity of each disturbance along the beam is indicated. 1-hop echoes within solid rectangles at ranges of 350-500 km reappear within dotted gray rectangles at ranges of $900-1100 \mathrm{~km}$ as 2-hop echoes.

these velocities are in line with the northward propagation velocities observed with the radar (see Fig. 5)). The velocities of $3.4-1.8 \mathrm{~km} / \mathrm{s}$ correspond to those of Rayleigh surface waves with periods of a few to a few tens of seconds (Oliver, 1962), and the velocity of $5.3 \mathrm{~km} / \mathrm{s}$ may belong to one of a primary $(P)$ wave, a secondary $(S)$ wave and a Rayleigh wave with a period of about a few hundreds of seconds or more (Brune et al., 1961b; Oliver, 1962). The radar began to detect the northward-propagating disturbance at $6.7 \mathrm{~km} / \mathrm{s}$ (see below) at around 1457 JST (Fig. 3). Though this disturbance from the epicenter is estimated to arrive at Moshiri at around 1448:03 JST, no appreciable signature was de- tected with the magnetometer (Figs. 4(b) and 4(c)). The most probable reason is that this magnetometer has very low sensitivity (Fig. 4(d)) for the $6.7 \mathrm{~km} / \mathrm{s}$ (also $5.3 \mathrm{~km} / \mathrm{s}$ ) wave.

The velocity type strong motion seismometer records from the NIED F-net stations in Japan (NIED F-net, 2011) show that seismic waves of $4.0-4.5 \mathrm{~km} / \mathrm{s}$ with small amplitude and also of $3.0-3.5 \mathrm{~km} / \mathrm{s}$ with large amplitude propagated northward. Though the northward-propagation of $5.3-6.7 \mathrm{~km} / \mathrm{s}$ waves is not clearly seen in the records, maybe because of their very small amplitudes, an F-net seismometer at Nishi-Okoppe, about $668 \mathrm{~km}$ from the epicenter and about $53 \mathrm{~km}$ ESE from Moshiri, detected an arrival of $\sim 6.7$ 
$\mathrm{km} / \mathrm{s}$ wave with small amplitude at around 1448 JST (NIED F-net, 2011), in line with the above-estimated arrival time (1448:03 JST) of this wave at Moshiri. It is noted that Brune et al. (1961a, b) and Bolt (1964) reported detection of waves of $5.5-6.7 \mathrm{~km} / \mathrm{s}$ or more on the ground.

The frequency spectra of three components $(d H / d t$, $d D / d t$ and $d Z / d t$ ) calculated by using the 64-Hz sampling data for 1448:00-1456:32 JST are displayed in Fig. 4(d). The spectra have peaks at $0.2-0.4 \mathrm{~Hz}$ (periods of $2.5-$ $5 \mathrm{~s}$ ), corresponding to the magnetometer shaking by the Rayleigh waves of $1.8-3.4 \mathrm{~km} / \mathrm{s}$ (see above). The frequency sensitivity of the magnetometer is also plotted in Fig. 4(d) with a solid curve (Shiokawa et al., 2010). Note that the sensitivities of the three components are almost identical. The sensitivity has a peak at around $3 \mathrm{~Hz}$ and decreases on both sides, meaning that the current magnetometer has no sensitivity for periods longer than $10 \mathrm{~s}$, in line with the fact that the magnetometer could detect no $6.7 \mathrm{~km} / \mathrm{s}$ wave with a period of about $600 \mathrm{~s}$ (Oliver, 1962) but a very weak signature of the $5.3 \mathrm{~km} / \mathrm{s}$ wave. It is known that electric field variations, generated by circular motion of ions in groundwater under the Earth's geomagnetic field, are observed during the passage of seismic wave. This process is called "seismic dynamo effect" (e.g., Honkura et al., 2009), and the observed frequencies were higher than about $10 \mathrm{~Hz}$ (Kuriki et al., 2011). Though the magnetometer has enough sensitivity at $10-20 \mathrm{~Hz}$, no such signatures are discernible in Fig. 4(d), indicating that the seismic dynamo effect was not operative in our case.

A routine ionosonde is located at Wakkanai $\left(45.16^{\circ} \mathrm{N}\right.$, $141.75^{\circ} \mathrm{E}$ ), about $90 \mathrm{~km}$ north of Moshiri and $762 \mathrm{~km}$ from the epicenter (Fig. 1). It is estimated that after passing Moshiri, the waves of $6.7-1.8 \mathrm{~km} / \mathrm{s}$ arrived at the ionosonde station during 1448:17-1453:26 JST. Acoustic waves excited by these waves on the ground are expected to propagate upward to attain to the $F$ region altitudes. By assuming an averaged upward sound velocity of 450-500 m/s (e.g., Yeh and Liu, 1974), it takes 500-556 s to arrive at the 250 $\mathrm{km}$ altitude. Maruyama et al. (2011) found the first peculiar "cusp" signatures at virtual altitudes of 200-300 km on the ionogram taken during 1458:15-1458:30 JST, but not during 1443:15-1443:30 JST (also see Liu and Sun, 2011). These signatures are believed to be related to the waves described above.

The waves of $6.7-1.8 \mathrm{~km} / \mathrm{s}$ are estimated to have arrived at the $1140 \mathrm{~km}$ points $(140 \mathrm{~km}$ north of the thick dotted-broken curve in Fig. 1) from the epicenter, that is, at around the $400 \mathrm{~km}$ range from Rikubetsu, during 14491457 JST. Then, the upward-propagating acoustic waves excited by these waves are expected to arrive at the 250 $\mathrm{km}$ altitude during about 1457-1505 JST, and to induce upward/downward plasma motion and focusing/defocusing of the radar waves. In fact, the initial disturbances triggered by the $6.7 \mathrm{~km} / \mathrm{s}$ wave were detected at 1457:15 JST with the radar, as shown in Fig. 3.

Figure 2(b) is again enlarged in Fig. 5. Note that the 1hop echoes within the solid rectangles at ranges of 350$500 \mathrm{~km}$ reappear at the same time at ranges of 900-1100 $\mathrm{km}$ within the dotted rectangles as 2-hop echoes. In this figure we can identify five oblique striations with nega- tive Doppler velocities between 1500:12 (start time of the themisscan) and 1510 JST, and one oblique striation with positive velocities during 1500:12-1501:30 JST. The striations with negative velocities have intervals of 1-2 min. These striations are believed to be caused by the northwardpropagating seismic surface waves with velocities of 6.7$1.8 \mathrm{~km} / \mathrm{s}$, as partly identified in the induction magnetometer record at Moshiri (Fig. 4) and the F-net seismometers. As shown in Fig. 3, the $6.7 \mathrm{~km} / \mathrm{s}$ disturbance started to be first detected at around $1457 \mathrm{JST}$. The $6.7 \mathrm{~km} / \mathrm{s}$ disturbance in Fig. 5 arrived at the radar FOV during 1459-1500 JST during which the normal scan was in operation, whereas the initial arrival of this disturbance was at around 1457 JST, being $\sim 2$ min earlier than 1459-1500 JST. Such a time difference may be due to that the $6.7 \mathrm{~km} / \mathrm{s}$ (also the $6.2 \mathrm{~km} / \mathrm{s}$ ) disturbance clearly seen in Fig. 5 was caused by acoustic waves propagating obliquely-upward toward the north from the Earth's surface.

From an initial analysis, Nishitani et al. (2011) identified the $6.2 \mathrm{~km} / \mathrm{s}$ disturbance with positive velocities between 1500:12 and 1501:30 JST and other disturbances of 3.5, 3.9 and $4.5 \mathrm{~km} / \mathrm{s}$, in line with the current analysis. The maximum peak-to-peak amplitude of the disturbances was about $200 \mathrm{~m} / \mathrm{s}(=2 v)$ at near ranges (Nishitani et al., 2011), corresponding to the actual upward and downward motions at $\pm 112 \mathrm{~m} / \mathrm{s}$ at a reflection altitude of $250 \mathrm{~km}$ at the $500 \mathrm{~km}$ ground range. Interestingly, there appear two weak striations with a northward velocity of $6.7 \mathrm{~km} / \mathrm{s}$ between 1513 and $1515 \mathrm{JST}$. We can find no big aftershocks to explain this wave propagation (see Section 3.1). One speculation at this stage is that seismic waves, originated at the epicenter by the mainshock, propagated over a long distance in the Earth's interior, and appeared on the ground near northern Hokkaido between 1505 and 1507 JST to induce the two northward-propagating disturbances at around 1513-1515 JST. This possibility should be checked in the future.

Figure 6 displays time and ground range variations of the Doppler velocity and echo power between 1458 and 1510 JST. The data with echo power higher than $20 \mathrm{~dB}$ are plotted. Again, the propagation velocity of each disturbance shown in Fig. 5 is overlaid in Figs. 6(a) and 6(b). The northward propagation of the waves of $3.3-6.7 \mathrm{~km} / \mathrm{s}$ seen before 1505 JST in Fig. 6(a) is also clearly discernible in Fig. 6(b), while that of $1.8-2.6 \mathrm{~km} / \mathrm{s}$ in Fig. 6(a) has no counterparts in Fig. 6(b). As described above, the Doppler velocity represents upward/downward motion of the reflection point in the ionosphere, while the echo power is modulated by focusing/defocusing of the radar waves. Therefore, our results indicate that two processes, that is, the rapid upward/downward motion exceeding, say, $|50| \mathrm{m} / \mathrm{s}$ (Nishitani et al., 2011) and the focusing/defocusing operated simultaneously before $1505 \mathrm{JST}$, whereas the latter process was ineffective at ranges beyond about $700 \mathrm{~km}$ after $1505 \mathrm{JST}$. It is pointed out that the echo powers in Fig. 6(b) exhibit modulation with a period of about $30 \mathrm{~s}$ at ranges of 500$700 \mathrm{~km}$ after $1503 \mathrm{JST}$, maybe indicating that the focusing and defocusing occurred with this period; however, no such modulation appear in the Doppler velocities in Fig. 6(a), suggesting no appreciable upward and downward motions associated with the focusing and defocusing. 

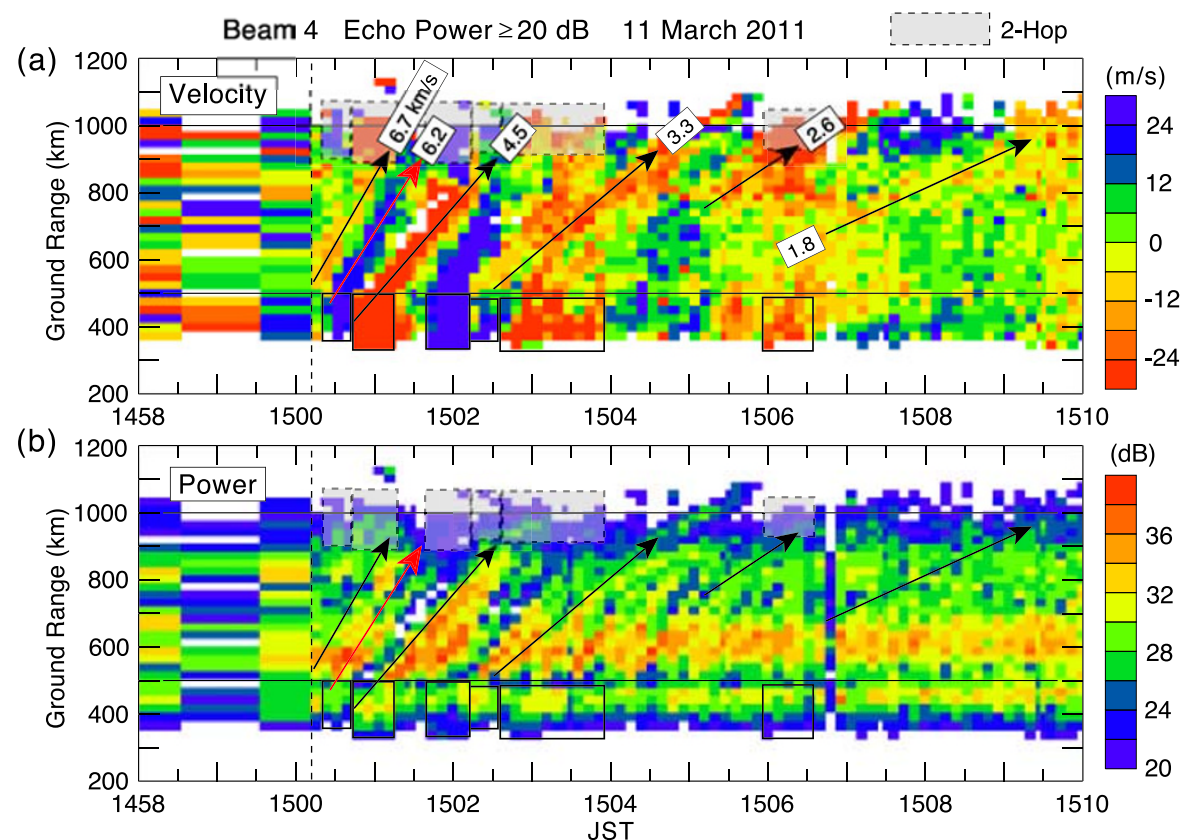

Fig. 6. Time and ground range variations of (a) Doppler velocity and (b) echo power on beam 4. Data with echo power higher than $20 \mathrm{~dB}$ are displayed. Echoes within dotted gray rectangles are contaminated by 2-hop echoes (see Fig. 5). Propagation velocity of each disturbance shown in (a) is overlaid in (b).

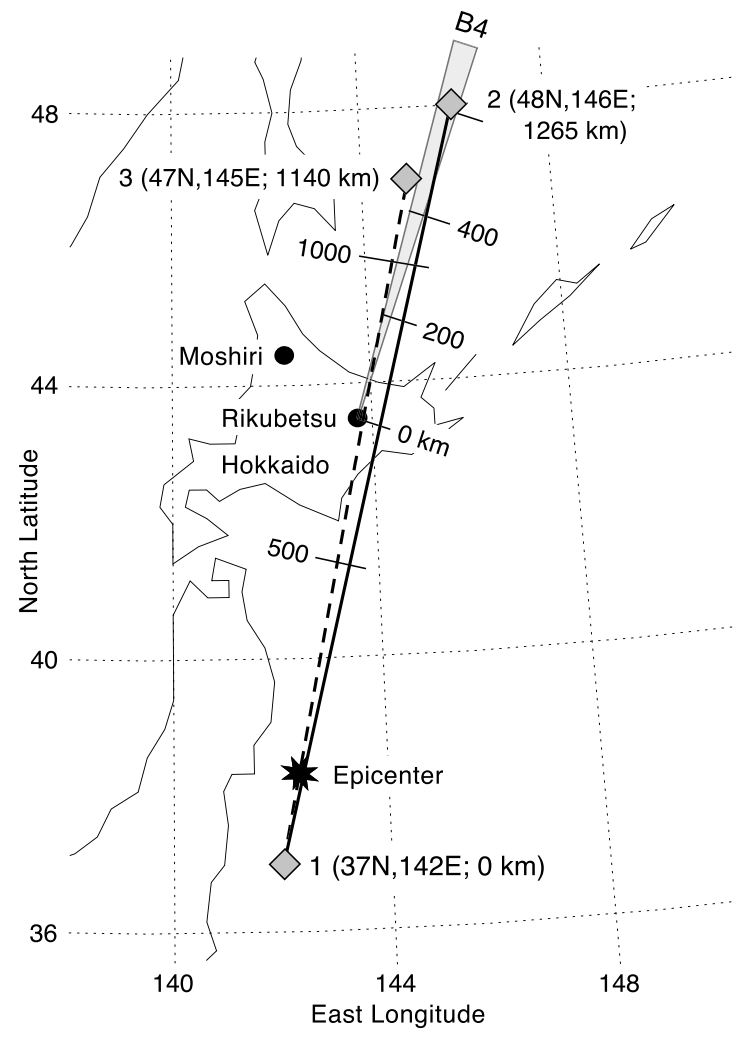

Fig. 7. Solid and broken straight lines along which TEC keograms are generated. Horizontal distances from point $1(0 \mathrm{~km})$ to points 2 (1265 km) and 3 $(1140 \mathrm{~km})$ and those from Rikubetsu along beam 4 are shown. The direction of beam 4 is closely aligned along two lines.

3.3 Comparison between radar echoes and GPS-TEC In this subsection, comparisons between the radar echoes and GPS-TEC during 1430-1730 JST in Fig. 2 are presented. A plot of time variation of GPS-TEC perturbation amplitudes along a straight line connecting two geographical points is called "keogram". We generate two TEC keograms along two lines shown in Fig. 7; that is, a solid line from point $1\left(37^{\circ} \mathrm{N}, 142^{\circ} \mathrm{E}\right.$; distance $\left.=0 \mathrm{~km}\right)$ to point 2 $\left(48^{\circ} \mathrm{N}, 146^{\circ} \mathrm{E} ; 1265 \mathrm{~km}\right)$, and a broken line from point 1 to point $3\left(47^{\circ} \mathrm{N}, 145^{\circ} \mathrm{E} ; 1140 \mathrm{~km}\right)$. The direction of beam 4 is closely aligned along the two lines, capable of making direct comparisons between the radar echoes and GPS-TEC. 
To generate the keogram, original TEC data (30-s sampling) from nine or ten GPS satellites were detrended by subtracting a 10-min running average, and then averaged over a width of $\sim 15 \mathrm{~km}$ on each side of the line. The detailed procedures to generate a keogram from two-dimensional GPSTEC maps is given by Tsugawa et al. (2011).

Figure 8(a) shows time and ground range variations of the echo power on beam 4. Data with echo power higher than $20 \mathrm{~dB}$ are displayed. The propagation velocity of each gravity wave shown in Fig. 2(a) is indicated. Figure 8(b) displays time and ground range variations of the Doppler velocity on beam 4 (see Fig. 2(b)) and TEC keogram along the solid line in Fig. 7. The TEC data with satellite elevation angles higher than $15^{\circ}$ are used in Fig. 8(b). In the figure the ordinate of the keogram represents the horizontal distance, and that of the Doppler velocity does the ground range from Rikubetsu: the $400 \mathrm{~km}$ ground range corresponds approximately to the $1140 \mathrm{~km}$ horizontal distance from point 1 in Fig. 7. The propagation velocity of each gravity wave shown in Fig. 8(a) is overlaid in Fig. 8(b). The TEC value is expressed in TEC units (TECU; one TECU $=10^{16}$ electrons $/ \mathrm{m}^{2}$ ). In the TEC keogram, successive northward-propagating waves $(187-287 \mathrm{~m} / \mathrm{s})$ from the epicenter (Fig. 1) are clearly seen during 1520-1640 JST. According to previous GPS-TEC observations (e.g., Artru et al., 2005; Rolland et al., 2010; Tsugawa et al., 2011), these waves can be categorized as AGW. These waves are also discernible in the power plot (136-343 m/s) in Figs. 2(a) and $8(\mathrm{a})$, but unclear in the velocity plot except for the $300 \mathrm{~m} / \mathrm{s}$ wave during 1615-1640 JST. We suppose that the waves brought about the focusing and defocusing of the radar waves, but were not accompanied by appreciable upward and downward motions of the reflection points. In addition to the gravity waves, the TEC keogram shows the waves of 667,747 and $862 \mathrm{~m} / \mathrm{s}$ during 1455-1525 JST that can be categorized as acoustic waves also from the epicenter. However, no counterparts are found in both the echo power and velocity plots: one of the reasons may be that these acoustic waves were not accompanied appreciable focusing and defocusing of the radar waves, neither upward and downward motions of the reflection points. Another reason may be due to subsidence of the acoustic waves before arriving at the radar FOV. Additionally, near the epicenter the TEC keogram shows clear long-lasting oscillations with a period of about $4 \mathrm{~min}$ due to the acoustic resonance (Saito et al., 2011; Tsugawa et al., 2011). The acoustic resonance observed with the radar will be discussed later.

To see the high-speed wave propagation in the GPS-TEC keogram, Fig. 9 using the same format of Fig. 8(b) displays time and ground range variations of the Doppler velocity on beam 4 and TEC keogram along the broken line in Fig. 7. The TEC data with satellite elevation angles higher than $15^{\circ}$ are used in Fig. 9. The propagation velocity of each disturbance shown in Fig. 5 is overlaid in the Doppler velocity plot. The TEC perturbations at $1.3 \mathrm{~km} / \mathrm{s}$ first arrived at the radar FOV (around $400 \mathrm{~km}$ range) at around $1506 \mathrm{JST}$. The TEC keogram indicates the northward-propagating, highspeed waves $(0.70,0.77,0.90$ and $1.3 \mathrm{~km} / \mathrm{s})$ after $1500 \mathrm{JST}$, but these waves have no counterparts in the echo power and Doppler velocity plots (also see Fig. 8). On the other hand, the waves of $1.8-6.7 \mathrm{~km} / \mathrm{s}$ in the velocity plot have no clear counterparts in the TEC keogram in which the waves of $1.8-3.3 \mathrm{~km} / \mathrm{s}$ seem to disappear at around $900 \mathrm{~km}$ from the epicenter. Tsugawa et al. (2011) have found a wave of about $3.5 \mathrm{~km} / \mathrm{s}$ that propagated westward from the ionospheric epicenter located at about $170 \mathrm{~km}$ southeast of the epicenter. In our case, this wave seems to disappear at around 900 $\mathrm{km}$ (oblique line of $3.5 \mathrm{~km} / \mathrm{s}$ ).

\subsection{Peculiar acoustic wave}

Doppler velocity oscillations at intervals of about 2-4 min due to the acoustic resonance were observed with the radar in periods 1, 2 and 3 indicated in Fig. 2(b). In period 1 (1520-1550 JST), though the velocity oscillations with a maximum peak-to-peak amplitude of $40 \mathrm{~m} / \mathrm{s}$ and a period of $4 \mathrm{~min}$ are recognized at ranges of $800-950 \mathrm{~km}$, the oscillations are not clear in time and space (see Fig. 2(b)). Figure 10(a) shows the Doppler velocity plot in period 2. The echoes within the dotted rectangle at ranges of 900 $1000 \mathrm{~km}$ may be contaminated by 2-hop echoes. The velocity oscillations with a maximum peak-to-peak amplitude of $30 \mathrm{~m} / \mathrm{s}$ are discernible at the nearest ranges during 1638 and $1700 \mathrm{JST}$ and at ranges of $800-850 \mathrm{~km}$ between $1638-1652$ JST. The Doppler velocity spectra at range gates of 16-17 (around the $400 \mathrm{~km}$ range) and 35-36 (around the $850 \mathrm{~km}$ range) during 1630-1702 JST are displayed in Fig. 10(b). The spectra have dominant and minor peaks at around 4 and 2 min, respectively, at range gates of 16-17, and a dominant peak at around $2.5 \mathrm{~min}$ at range gates of 35-36. Such oscillations are also discernible at ranges beyond $1000 \mathrm{~km}$.

Another example in period 3 in Fig. 2(b) is shown in Fig. 10 (c). During 1750-1830 JST there appear clear velocity oscillations with a maximum peak-to-peak amplitude of $60 \mathrm{~m} / \mathrm{s}$ at ranges of $500-800 \mathrm{~km}$ and with a maximum peak-to-peak amplitude of $30 \mathrm{~m} / \mathrm{s}$ at ranges of $800-1000$ $\mathrm{km}$. The velocity spectra at range gates of 25-26 (around $600 \mathrm{~km}$ range) and 36-37 (around 850-900 km ranges) during 1750-1822 JST are displayed in Fig. 10(d), where the dominant spectral peaks are around $3 \mathrm{~min}$.

By using the same format as Fig. 8(b), Fig. 11(a) compares the Doppler velocity with GPS-TEC. The TEC data with satellite elevation angles higher than $30^{\circ}$ are used to generate the keogram along the solid line in Fig. 7. When the 3-min oscillations are observed during 1750-1830 JST at ranges of 500-1000 km (see Fig. 10(c)), there appear rather irregular, wavy structures in TEC during 1730-1840 JST at horizontal distances of 600-900 km. Though the radar echo and TEC regions exhibiting such oscillations do not overlap in space each other, we think that these oscillations are caused by the acoustic resonance. Figure 11(b) displays two-dimensional maps of the velocity every 2 min during 1758-1810 JST. In the figure the positive (negative) Doppler velocity regions are surrounded by the solid (dotted) rectangles. These regions with an E-W wavelength of about $400 \mathrm{~km}$ apparently move westward at about $1.6 \mathrm{~km} / \mathrm{s}$. Simultaneously, the slow northward movement of these regions is discernible, as can be clearly recognized between 1806 and 1822 JST at ranges of 550-750 km in Fig. 10(c). As an example, the two-dimensional map of the Doppler velocity during 1804-1806 JST and TEC at 1805 JST is shown in Fig. 11(c), where the resonance region with deep 


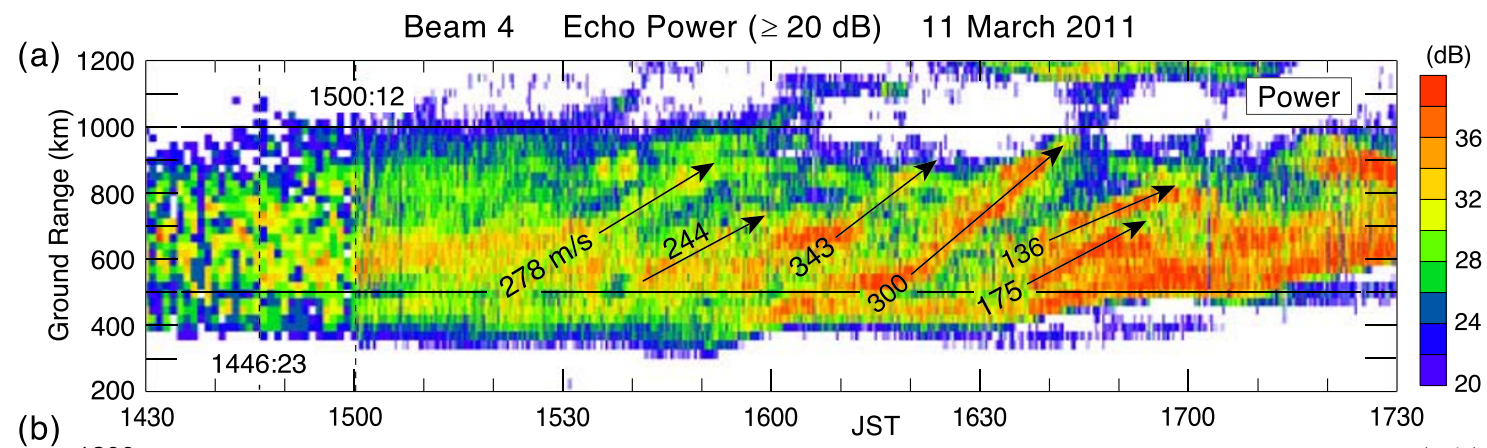

(b)

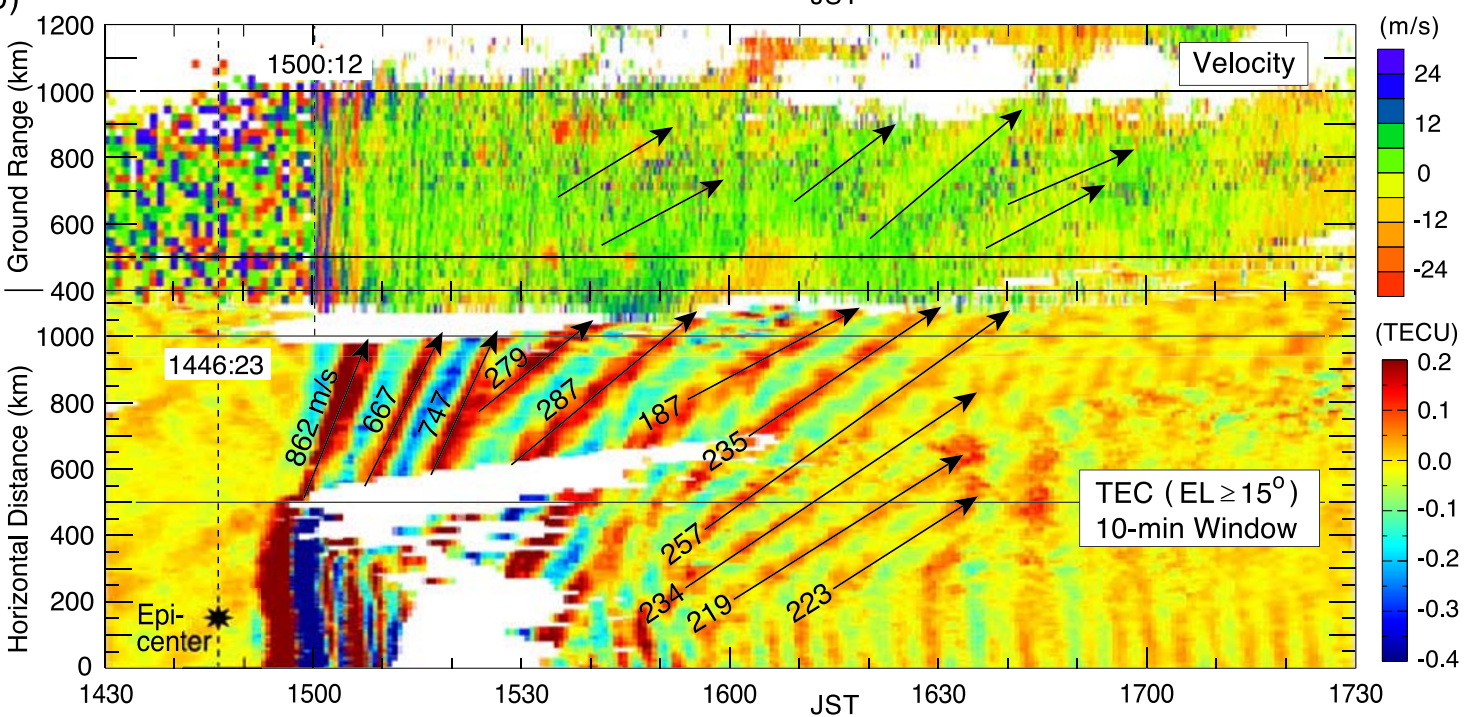

Fig. 8. (a) Time and ground range variations of echo power (with power higher than $20 \mathrm{~dB}$ ) on beam 4 . Propagation velocity of each gravity wave shown in Fig. 2(a) is again indicated. (b) Time and ground range variations of Doppler velocity on beam 4 and GPS-TEC keogram along the solid line in Fig. 7. Propagation velocity of each gravity wave shown in (a) is overlaid in the Doppler velocity plot in (b).

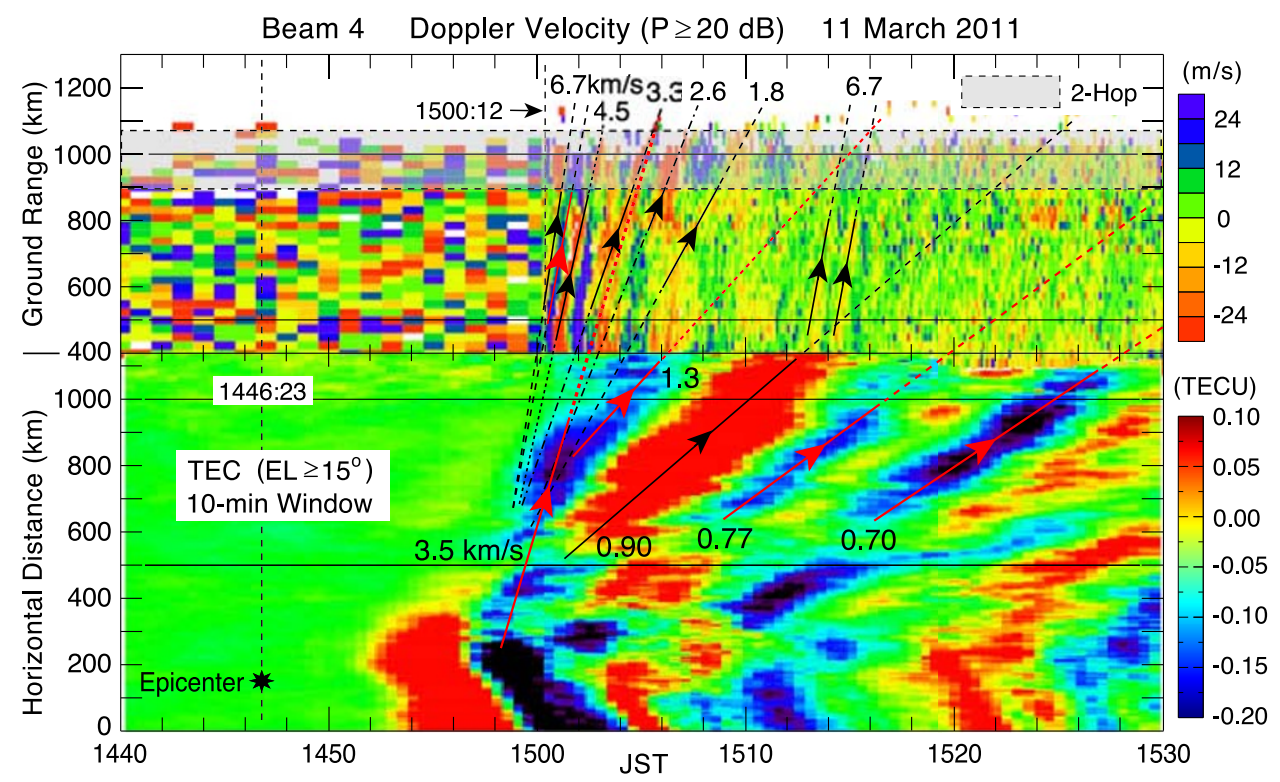

Fig. 9. Time and ground range variations of Doppler velocity (with echo power higher than $20 \mathrm{~dB}$ ) on beam 4 and GPS-TEC keogram along the broken line in Fig. 7. Echoes within a dotted gray rectangle are partly contaminated by 2 -hop echoes.

negative and positive TEC perturbations is localized in the eastern part of Hokkaido. Unfortunately, the GEONET do not provide TEC data within the radar echo regions, which makes a direct comparison of the resonance features impossible.

\section{Results and Discussion}

Using data from the HF radar and GEONET, we have analyzed ionospheric disturbance events caused by the 2011 Tohoku earthquake on 11 March 2011. The results are as follows: 

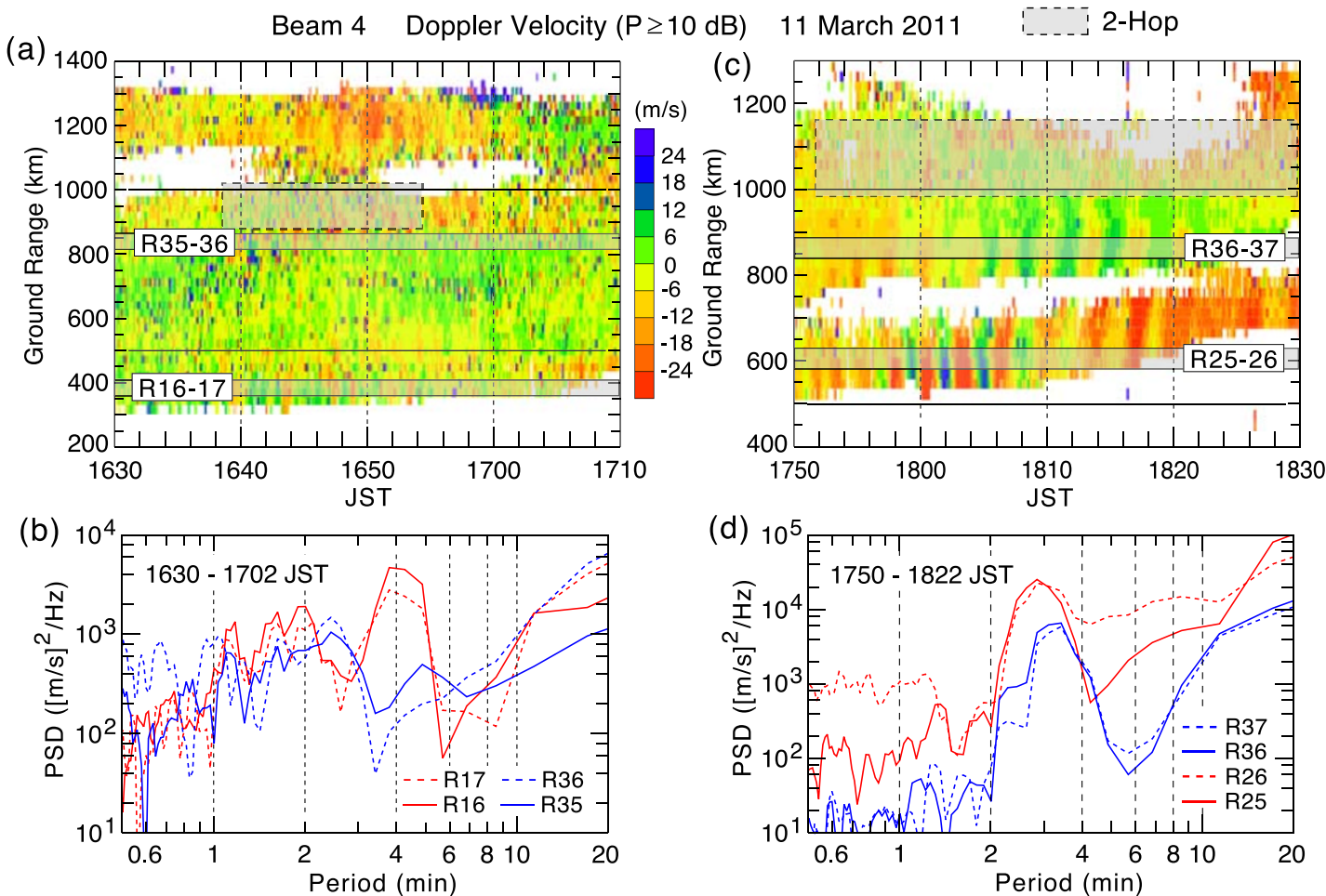

Fig. 10. (a) and (c) Time and ground range variations of Doppler velocity (with echo power higher than $10 \mathrm{~dB}$ ) on beam 4 . Echoes within dotted gray rectangles are partly contaminated by 2-hop echoes. (b) and (d) Doppler velocity spectra at four range gates.
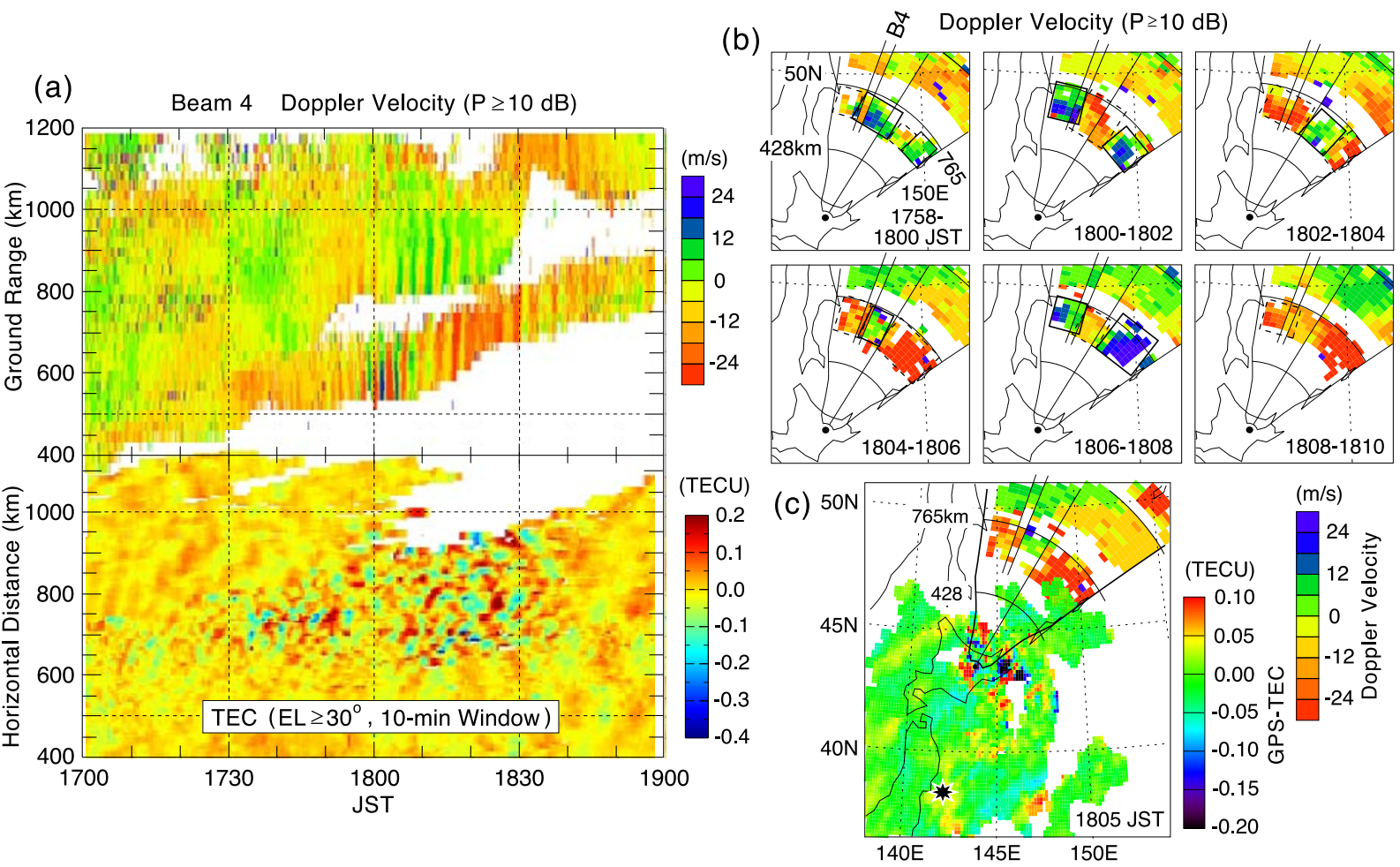

Fig. 11. (a) Time and ground range variations of Doppler velocity on beam 4 (Fig. 10(c)) and GPS-TEC keogram along the solid line in Fig. 7, using the same format as Fig. 8(b). (b) Time variation of Doppler velocity map every 2 min. Positive and negative Doppler velocity regions are surrounded by solid and dotted rectangles, respectively. Beam 4 is marked in each figure. (c) Map of Doppler velocity during $1804-1806$ JST and TEC at 1805 JST. 


\subsection{Propagation of $6.7-1.8 \mathrm{~km} / \mathrm{s}$ waves}

During the normalscan of the radar with 1-min time resolution, northward-propagating disturbances from the epicenter were first detected on the radar beam 10 at 1457:15 JST, 10 min $52 \mathrm{~s}$ later after the mainshock at 1446:23 JST, and then successively on other beams (Fig. 3). After start of the themisscan at 1500:12 JST with 8-s resolution on beam 4 and 2-min one on other beams, the radar observed clear northward-propagating disturbances with high velocities on beam 4 until 1508 JST (Fig. 5). As also found by Nishitani et al. (2011), the horizontal propagation velocities exhibited clear velocity dispersion, that is, changed from 6.7 to $1.8 \mathrm{~km} / \mathrm{s}$ with time. We believe that acoustic waves excited on the Earth's surface by these high-speed waves, whose velocities are much higher than the sound velocity in the atmosphere, propagated upward and obliquely-upward to attain to the $F$ region ( $250 \mathrm{~km}$ altitude) and then to induce the current ionospheric disturbances. Observed Doppler velocities with a maximum of about $|100| \mathrm{m} / \mathrm{s}$ fluctuated at intervals of 1-2 min. Previously, oscillations with periods of $1-2$ min caused by $\sim 3.5-4.2 \mathrm{~km} / \mathrm{s}$ Rayleigh wave propagation in association with earthquakes were observed by $10-\mathrm{MHz}$ HF-Doppler sounding (Najita and Yuen, 1979). Additionally, there appeared again a weak signature of the northward propagation at $6.7 \mathrm{~km} / \mathrm{s}$ between 1513 and 1515 JST. At this stage, we speculate that seismic waves, triggered by the mainshock, propagated over a long distance in the Earth's interior, and then brought about this propagation on the Earth's surface.

The current waves induced mechanical shaking of an induction magnetometer at Moshiri (Fig. 4). The magnetometer data indicate the propagation of the waves of 5.3-1.8 $\mathrm{km} / \mathrm{s}$, in line with that of $4.5-1.8 \mathrm{~km} / \mathrm{s}$ in Fig. 5. Though no appreciable signatures of 6.7 and $6.2 \mathrm{~km} / \mathrm{s}$ waves were found in the F-net seismometer records, perhaps because of very low sensitivity for these waves, a seismometer near Moshiri indicated a signature of these waves (see Section 3.2).

Past observations showed wave propagation at 3.5-4.2 km/s caused by Rayleigh waves (e.g., Najita and Yuen, 1979; Tanaka et al., 1984; Ducic et al., 2003). For the current earthquake, Nishitani et al. (2011) have identified $3.5-6.2 \mathrm{~km} / \mathrm{s}$ waves toward the north. Here, we find other waves of $6.7,2.6$ and $1.8 \mathrm{~km} / \mathrm{s}$. As far as we know, this paper reports first the $6.7 \mathrm{~km} / \mathrm{s}$ wave. Using GPS-TEC data, Tsugawa et al. (2011) have found $3.5 \mathrm{~km} / \mathrm{s}$ wave propagation toward the west (also see Rolland et al., 2011a; Liu and Sun, 2011). Our TEC keogram nearly along N-S (Fig. 9) indicates that the waves of $4.5-6.7 \mathrm{~km} / \mathrm{s}$ seen in the Doppler velocity plot have no counterparts in the keogram, and those of $1.8-3.3 \mathrm{~km} / \mathrm{s}$ seen in the keogram disappear near a horizontal distance of $900 \mathrm{~km}$ from the epicenter before arriving at the radar FOV. To judge whether this disappearance is true or not, careful analysis using 1-s sampling TEC data is required in the future.

\subsection{Propagation of acoustic and gravity waves}

During 1530-1700 JST the radar detected northwardpropagating waves $(136-343 \mathrm{~m} / \mathrm{s}$; Fig. 2(a)) due to northward-propagating AGW excited somewhere by the earthquake and/or tsunamis. Similar AGW are also seen in the TEC keogram in Fig. 8(b). Radial propagation of AGW from the epicenter or the ionospheric epicenter has been discussed by many researchers (e.g., Calais and Minster, 1995; Artru et al., 2004; Otsuka et al., 2006; Shinagawa et al., 2007; Tsugawa et al., 2011; Liu and Sun, 2011; Rolland et al., 2011a; Matsumura et al., 2011). Though the radiallypropagating acoustic waves of $0.7-1.3 \mathrm{~km} / \mathrm{s}$ are discernible in the TEC keograms in Figs. 8(b) and 9, such propagation could not been observed with the radar. One reason may be that these acoustic waves were not accompanied by rapid upward and downward motions of the $F$ region plasma to induce high Doppler shifts and also by deep plasma density fluctuation to induce focusing and defocusing of the radar waves. Another reason may be due to subsidence of acoustic waves before arriving at the radar FOV. In addition to these reasons, we note the difference in the observation technique (see Section 2); that is, GPS-TEC is sensitive to the electron density distribution mainly at the $250-350 \mathrm{~km}$ altitudes, while the HF radar probes plasma disturbances at around the $250 \mathrm{~km}$ altitude, and therefore, if the current acoustic waves propagated above the $250 \mathrm{~km}$ altitude, the radar could not clearly detect them. It is impossible to pursue the above-described inconsistency between the radar and TEC results more, mainly because the radar FOV and the GEONET coverage do not overlap each other. Such discussions are also helpful to understand why the 1.8-6.7 $\mathrm{km} / \mathrm{s}$ wave propagation observed with the radar have no clear counterparts in the TEC keogram (Fig. 9; Section 4.1).

It is noted that ionospheric disturbances with a horizontal velocity of about $300 \mathrm{~m} / \mathrm{s}$ propagated over Japan after big volcanic eruptions that occurred far away from Japan (Ogawa et al., 1982; Igarashi et al., 1994).

\subsection{Acoustic resonance}

Peculiar radar echoes due to the acoustic resonance were detected in periods 1, 2 and 3 indicated in Fig. 2. Their Doppler velocities oscillate with periods of about 2-4 min (Fig. 10). In particular, when clear 3-min oscillations were observed during 1750-1830 JST, there appeared almost simultaneously rather irregular, wavy structures in TEC to the south of the radar FOV. The 3-min oscillation region had an E-W wavelength of about $400 \mathrm{~km}$ and apparently moved westward at about $1.6 \mathrm{~km} / \mathrm{s}$. Using 1-s sampling TEC data, Saito et al. (2011) have found that the TEC spectrum had a dominant peak at $222 \mathrm{~s}$ and two minor peaks at $188 \mathrm{~s}$ and $268 \mathrm{~s}$ caused by the acoustic resonance, in line with our results. According to Saito et al. (2011), the acoustic resonance was detected continuously for four hours within the region of $35^{\circ}-39^{\circ} \mathrm{N}$ and $139^{\circ}-146^{\circ} \mathrm{E}$ near the epicenter (see also Rolland et al., 2011a; Tsugawa et al., 2011; Fig. 8(b)). In our case, the resonance continued for about two hours after 1630 JST (Figs. 10 and 11), and its region was located to the north of the GEONET coverage. As shown in Fig. 11, the resonance during 1730-1840 JST is coincident with that seen in TEC in the eastern part of Hokkaido. Except for periods 1, 2 and 3 in Fig. 2, no appreciable resonance phenomena were detected with the radar, maybe indicating that the resonant oscillations at northern latitudes higher than, say, $40^{\circ} \mathrm{N}$ were not continuous in time, but intermittent and weak.

The resonant frequencies described above are consistent 
with those from numerical simulations by Shinagawa et al. (2007) and Matsumura et al. (2011) who also simulated long-distance propagation of gravity waves that were produced in the thermosphere through acoustic pulse from the epicenter.

As stated in Section 4.2, the radially-propagating acoustic waves at $0.7-1.3 \mathrm{~km} / \mathrm{s}$ seen in the TEC data have no counterparts in the radar data. However, as stated above, the acoustic resonance was occasionally detected with the radar. This resonance is believed to be due to the modal resonance of upward- and downward-propagating acoustic waves between the ground surface and the lower thermosphere (e.g., Saito et al., 2011). Some part of resonant wave energy leaks upward, and generate upward and downward motions of the $F$ region plasma to be detected with the radar and GEONET.

\section{Conclusions}

SuperDARN Hokkaido HF radar observations revealed many interesting features of the giant ionospheric disturbances over the Sea of Okhotsk that were induced by the 2011 Tohoku earthquake. Fortunately, an incidental "themisscan" operation clarified detailed characteristics of wavy structures propagating northward along the radar beam 4. Initial disturbances arrived at the radar FOV at around 1457 JST, about 11 min later after the mainshock. After this time, disturbance regions with negative and positive Doppler shifts at intervals of 1-2 min successively propagated northward at velocities of $6.7-1.8 \mathrm{~km} / \mathrm{s}$, being attributable to the seismic surface waves from the epicenter. As far as we know, this paper first finds a $6.7 \mathrm{~km} / \mathrm{s}$ wave in the $F$ region ionosphere. An induction magnetometer at Moshiri was mechanically shaken by seismic waves with periods of 2.5-5 s, corresponding to the Rayleigh waves of $1.8-3.4 \mathrm{~km} / \mathrm{s}$. After passage of $6.7-1.8 \mathrm{~km} / \mathrm{s}$ waves, during 1530-1700 JST there appeared northward-propagating disturbances (136-343 m/s) due to AGW perhaps excited near the epicenter.

Observation regions of GEONET is on the south of the radar FOV. Comparisons between GPS-TEC and radar observations indicate the following: (1) Waves of 4.5-6.7 $\mathrm{km} / \mathrm{s}$ observed with the radar have no counterparts in TEC, and those of $1.8-3.3 \mathrm{~km} / \mathrm{s}$ observed with the radar seem to disappear in TEC before arriving at the radar FOV. (2) Acoustic waves of $0.7-1.3 \mathrm{~km} / \mathrm{s}$ identified in TEC have no counterparts in the radar data. (3) Disturbances caused by AGW are discernible in both TEC and radar data. (4) Disturbances due to acoustic resonance are simultaneously identified in both TEC (periods of about 2-4 min) and radar data. This is the first observation of the acoustic resonance with radar. Again we note that due to the difference in observation technique, the results from the radar are not always consistent with those from GPS-TEC (see Section 4.2).

We used GS-scatter echoes to observe daytime ionospheric disturbances. Useful echoes could be detected when relatively high upward and downward motions of ionospheric reflection point appeared and/or when strong focusing and defocusing of the radar waves were operative. If both processes did not well operate for traveling waves, it was impossible to detect these waves. As demonstrated in this paper, a sophisticated HF radar can reveal new ionospheric disturbance features.

Acknowledgments. We thank all the staff who contributed to the HF radar experiment at Hokkaido, and M. Teramoto and $\mathrm{K}$. Sakaguchi for their kind support to data analyses. GPS data of GEONET were provided by the Geospatial Information Authority of Japan. This work was supported by a Grant-in-Aid for Scientific Research of the Ministry of Education, Culture, Sports, Science and Technology (MEXT) of Japan (19340141), and also by Special Funds for Education and Research (Energy Transport Processes in Geospace) of MEXT. We are grateful to two referees for their helpful comments and suggestions.

\section{References}

Afraimovich, E. L., N. P. Perevalova, A. V. Plotnikov, and A. M. Uralov, The shock-acoustic waves generated by the earthquakes, Ann. Geophys., 19, 395-409, 2001

Artru, J., T. Farges, and P. Lognonné, Acoustic waves generated from seismic surface waves: propagation properties determined from Doppler sounding observations and normal-mode modelling, Geophys. J. Int., 158, 1067-1077, 2004.

Artru, J., V Ducic, H. Kanamori, P. Lognonné, and M. Murakami, Ionospheric detection of gravity waves induced tsunamis, Geophys. J. Int., 160, 840-845, 2005.

Astafyeva, E., K. Heki, V. Kiryushkin, E. Afraimovich, and S. Shalimov, Two-mode long-distance propagation of coseismic ionosphere disturbances, J. Geophys. Res., 114, A10307, doi:10.1029/2008JA013853, 2009.

Blanc, E., Observations in the upper atmosphere of infrasonic waves from natural or artificial sources: A summary, Ann. Geophys., 3, 673-688, 1985.

Bolt, B. A., Seismic air waves from the great 1964 Alaskan earthquake, Nature, 202, 1095-1096, 1964.

Brune, J., M. Ewing, and J. Kuo, Group and phase velocities for Rayleigh waves of period greater than 380 seconds, Science, 133(\#3455), 757 758, 1961a.

Brune, J. N., H. Benioff, and M. Ewing, Long-period surface waves from the Chilean earthquake of May 22, 1960, recorded on linear strain seismographs, J. Geophys. Res., 66, 2895-2910, 1961b.

Calais, E. and J. B. Minster, GPS detection of ionospheric perturbations following the January 17, 1994, Northridge earthquake, Geophys. Res. Lett., 22, 1045-1048, 1995.

Chen, C. H., A. Saito, C. H. Lin, J. Y. Liu, H. F. Tsai, T. Tsugawa, Y. Otsuka, M. Nishioka, and M. Matsumura, Long-distance propagation of ionospheric disturbance generated by the 2011 off the Pacific coast of Tohoku Earthquake, Earth Planets Space, 63, 881-884, 2011.

Chisham, G. et al., A decade of the Super Dual Auroral Radar Network (SuperDARN): scientific achievements, new techniques and future directions, Surv. Geophys., 28, 22-109, 2007.

Ducic, V., J. Artru, and P. Lognonné, Ionospheric remote sensing of the Denali Earthquake Rayleigh surface waves, Geophys. Res. Lett., 30, 1951, doi:10.1029/2003GL017812, 2003.

Greenwald, R. A. et al., DARN/SuperDARN: A global view of the dynamics of high-latitude convection, Space Sci. Rev., 71, 761-796, 1995.

Heki, K. and J. S. Ping, Directivity and apparent velocity of the coseismic ionospheric disturbances observed with a dense GPS array, Earth Planet. Sci. Lett., 236, 845-855, 2005.

Honkura, Y., Y. Ogawa, M. Matsushima, S. Nagaoka, N. Ujihara, and T. Yamawaki, A model for observed circular polarized electric fields coincident with the passage of large seismic waves, J. Geophys. Res., 114, B10103, doi:10.1029/2008JB006117, 2009.

Igarashi, K., S. Kainuma, I. Nishimuta, S. Okamoto, H. Kuroiwa, T. Tanaka, and T. Ogawa, Ionospheric and atmospheric disturbances around Japan caused by the eruption of Mount Pinatubo on 15 June 1991, J. Atmos. Terr. Phys., 56, 1227-1234, 1994.

Kelley, M. C., R. Livingston, and M. McCready, Large amplitude thermospheric oscillations induced by an earthquake, Geophys. Res. Lett., 12, 577-580, 1985.

Kuriki, M., M. Matsushima, Y. Ogawa, and Y. Honkura, Spectral peaks in electric field at resonance frequencies for seismically excited motion of ions in the Earth's magnetic field, Earth Planets Space, 63, 503-507, 
2011.

Leonard, R. S. and R. A. Barnes, Observation of ionospheric disturbances following the Alaska earthquake, J. Geophys. Res., 70, 1250-1253, 1965.

Liu, J.-Y. and Y.-Y. Sun, Seismo-traveling ionospheric disturbances of ionograms observed during the $2011 M_{\mathrm{w}} 9.0$ Tohoku Earthquake, Earth Planets Space, 63, 897-902, 2011.

Liu, J. Y., Y. B. Tsai, S. W. Chen, C. P. Lee, Y. C. Chen, H. Y. Yen, W. Y. Chang, and C. Liu, Giant ionospheric disturbances excited by the M9.3 Sumatra earthquake of 26 December 2004, Geophys. Res. Lett., 33, L02103, doi:10.1029/2005GL023963, 2006.

Liu, J. Y., H. F. Tsai, C. H. Lin, M. Kamogawa, Y. I. Chen, C. H. Lin, B. S. Huang, S. B. Yu, and Y. H. Yeh, Coseismic ionospheric disturbances triggered by the Chi-Chi earthquake, J. Geophys. Res., 115, A08303, doi:10.1029/2009JA014943, 2010.

Liu, J. Y., C. H. Chen, C. H. Lin, H. F. Tsai, C. H. Chen, and M. Kamogawa, Ionospheric disturbances triggered by the 11 March 2011 M9.0 Tohoku earthquake, J. Geophys. Res., 116, A06319, doi:10.1029/2011JA016761, 2011.

Maruyama, T., T. Tsugawa, H. Kato, A. Saito, Y. Otsuka, and M. Nishioka, Ionospheric multiple stratifications and irregularities induced by the 2011 off the Pacific coast of Tohoku Earthquake, Earth Planets Space, 63, 869-873, 2011.

Matsumura, M., A. Saito, T. Iyemori, H. Shinagawa, T. Tsugawa, Y. Otsuka, M. Nishioka, and C. H. Chen, Numerical simulations of atmospheric waves excited by the 2011 off the Pacific coast of Tohoku Earthquake, Earth Planets Space, 63, 885-889, 2011.

Najita, K. and P. C. Yuen, Long-period oceanic Rayleigh wave group velocity dispersion curve from HF Doppler sounding of the ionosphere, J. Geophys. Res., 84, 1253-1260, 1979.

NIED F-net, http://www.fnet.bosai.go.jp/top.php, 2011.

Nishitani, N. and T. Ogawa, Model calculations of possible ionospheric backscatter echo area for a mid-latitude HF radar, Adv. Polar Upper Atmos. Res., 19, 55-62, 2005.

Nishitani, N., T. Ogawa, Y. Otsuka, K. Hosokawa, and T. Hori, Propagation of large amplitude ionospheric disturbances with velocity dispersion observed by the SuperDARN Hokkaido radar after the 2011 off the Pacific coast of Tohoku Earthquake, Earth Planets Space, 63, 891-896, 2011.

Occhipinti, G., P. Dorey, T. Farges, and P. Lognonné, Nostradams: The radar that wanted to be a seismometer, Geophys. Res. Lett., 37, L18104, doi:10.1029/2010GL044009, 2010.

Ogawa, T., H. Kumagai, and K. Sinno, Ionospheric disturbances over Japan due to the 18 May 1980 eruption of Mount St. Helens, J. Atmos. Terr. Phys., 44, 863-868, 1982.

Ogawa, T., N. Nishitani, Y. Otsuka, K. Shiokawa, T. Tsugawa, and K. Hosokawa, Medium-scale traveling ionospheric disturbances observed with the SuperDARN Hokkaido radar, all-sky imager, and GPS network and their relation to concurrent sporadic E irregularities, J. Geophys. Res., 114, A03316, doi:10.1029/2008JA013893, 2009.

Oliver, J., A summary of observed seismic surface wave dispersion, Bull. Seismol. Soc. Am., 52, 81-86, 1962.

Otsuka, Y. et al., GPS detection of total electron content variations over Indonesia and Thailand following the 26 December 2004 earthquake, Earth Planets Space, 58, 159-165, 2006.
Rolland, L. M., G. Occhipinti, P. Lognonné, and A. Loevenbruck, Ionospheric gravity waves detected offshore Hawaii after tsunamis, Geophys. Res. Lett., 37, L17101, doi:10.1029/2010GL044479, 2010.

Rolland, L. M., P. Lognonné, E. Astafyeva, E. A. Kherani, N. Kobayashi, M. Mann, and H. Munekane, The resonant response of the ionosphere imaged after the 2011 off the Pacific coast of Tohoku Earthquake, Earth Planets Space, 63, 853-857, 2011a.

Rolland, L. M., P. Lognonné, and H. Munekane, Detection and modelling of Rayleigh wave induced patterns in the ionosphere, J. Geophys. Res., 116, A05320, doi:10.1029/2010JA016060, 2011b.

Saito, A., T. Tsugawa, Y. Otsuka, M. Nishioka, T. Iyemori, M. Matsumura, S. Saito, C. H. Chen, Y. Goi, and N. Choosakul, Acoustic resonance and plasma depletion detected by GPS total electron content observation after the 2011 off the Pacific coast of Tohoku Earthquake, Earth Planets Space, 63, 863-867, 2011.

Samson, J. C., R. A. Greenwald, J. M. Ruohoniemi, A. Frey, and K. B. Baker, Goose Bay radar observations of Earth-reflected, atmospheric gravity waves in the high-latitude ionosphere, J. Geophys. Res., 95, 7693-7709, 1990.

Shinagawa, H., T. Iyemori, S. Saito, and T. Maruyama, A numerical simulation of ionospheric and atmospheric variations associated with the Sumatra earthquake on December 26, 2004, Earth Planets Space, 59, 1015-1026, 2007.

Shiokawa, K., Y. Otsuka, N. Nishitani, T. Ogawa, T. Tsugawa, T. Maruyama, S. E. Smirnov, V. V. Bychkov, and B. M. Shevtsov, Northeastward motion of nighttime medium-scale traveling ionospheric disturbances at middle latitudes observed by an airglow imager, J. Geophys. Res., 113, A12312, doi:10.1029/2008JA013417, 2008.

Shiokawa, K. et al., The STEL induction magnetometer network for observation of high-frequency geomagnetic pulsations, Earth Planets Space, 62, 517-524, 2010.

Suzuki, S., K. Hosokawa, Y. Otsuka, K. Shiokawa, T. Ogawa, N. Nishitani, T. F. Shibata, A. V. Koustov, and B. M. Shevtsov, Coordinated observations of nighttime medium-scale traveling ionospheric disturbances in 630-nm airglow and HF radar echoes at midlatitudes, J. Geophys. Res., 114, A07312, doi:10.1029/2008JA013963, 2009.

Tanaka, T., T. Ichinose, T. Okuzawa, T. Shibata, Y. Sato, C. Nagasawa, and T. Ogawa, HF-Doppler observations of acoustic waves excited by the Urakawa-oki earthquake on 21 March 1982, J. Atmos. Terr. Phys., 46, 233-245, 1984.

Tsugawa, T., A. Saito, Y. Otsuka, M. Nishioka, T. Maruyama, H. Kato, T. Nagatsuma, and K. T. Murata, Ionospheric disturbances detected by GPS total electron content observation after the 2011 off the Pacific coast of Tohoku Earthquake, Earth Planets Space, 63, 875-879, 2011. U.S. Geological Survey, http://earthquake.usgs.gov/, 2011.

Yeh, K. C. and C. H. Liu, Acoustic-gravity waves in the upper atmosphere, Rev. Geophys. Space Phys., 12, 193-216, 1974.

Yuen, P. C., P. F. Weaver, and R. K. Suzuki, Continuous, traveling coupling between seismic waves and the ionosphere evident in May 1968 Japan earthquake data, J. Geophys. Res., 74, 2256-2264, 1969.

T. Ogawa (e-mail: taogawa@nict.go.jp), N. Nishitani, T. Tsugawa, and K. Shiokawa 